\title{
USING dBASE II FOR RETRIEVAL OF RADIOCARBON DATA*
}

\author{
LOTTE SELSING and AUD SIMONSEN \\ Arkeologisk museum i Stavanger, P O Box 478, N-400 1 \\ Stavanger, Norway
}

\begin{abstract}
A "C:14" data base has been created for internal use of ${ }^{14} \mathrm{C}$ dates with an Osborne-1 system. It uses a CP/M operating system, Z-80 CPU, and dBASE II software program. The structure meets the users' requirements of information and easy retrieval. The video display is quite compact, as a record of 32 ficlds is edited to fill a screen of 22 lines. A standard printout is edited to make room for two records per page and contains all information from these records. Searching may take place in all ficlds or parts of fields, in interval(s) in one or more fields and in various combinations of the prescribed methods of searching. A field called KEYWORDS is established to ease search operations. "C.14" may be adapted to individual requirements and equipment with small adjustments.
\end{abstract}

\section{INTRODUCTION}

The "C14" data base has been created for internal use at any institution using ${ }^{14} \mathrm{C}$ dates. The data base may also be used for submitting dates for publication in Radiocarbon. It is not linked with other data base systems but has been established to routincly provide a survey of published and unpublished dates.

\section{HARDWARE AND SOFTWARE}

We have used Osborne-1 (Ashton-Tate) using a CP/M operating system and Z-80 CPU. We use dBASE II-a fourth generation programming language.

Each record in $\mathrm{DBASE}$ II has a limit of 32 fields and each field is limited to 254 characters. The maximum number of characters per record is 1000 . Five 1/4" diskettes are used. They can hold ca 200,000 characters. Each of the records in our "C14" data base has 1000 characters. Thus, one diskette may hold ca 200 records, but we have chosen to fill up $2 / 3$ of each diskette to allow for manipulation of the data base, such as sorting files and extracting data to temporary files. In order to get an overview of more than one diskette at the time, a hard disk is required.

\section{STRUCTURE}

The structure of the data base is derived from a specific form used by submitters and the Radiological Dating Laboratory, Trondheim, Norway, upon publication of a ${ }^{14} \mathrm{C}$ date in Radiocarbon (Fig 1). This form has been revised, taking into consideration the multidisciplinary background of the users of ${ }^{14} \mathrm{C}$ dates, and adapted to fit dBASE II. The structure (Fig 2) has 32 fields, which forms one record and is appropriate for our use as well as an up-to-date international record. Some submitters have particular interests which we assume, can be adapted to a relatively large field of keywords for a wide variety of subjects. ${ }^{14} \mathrm{C}$ laboratories need to store specific information, eg, amount of gas measured, and pretreatment of the samples. We propose that the laboratories maintain an extra record for each date in a secondary

*This poster presentation was made at the 12 th International Radiocarbon Conference, June 24-28, Trondheim, Norway. 


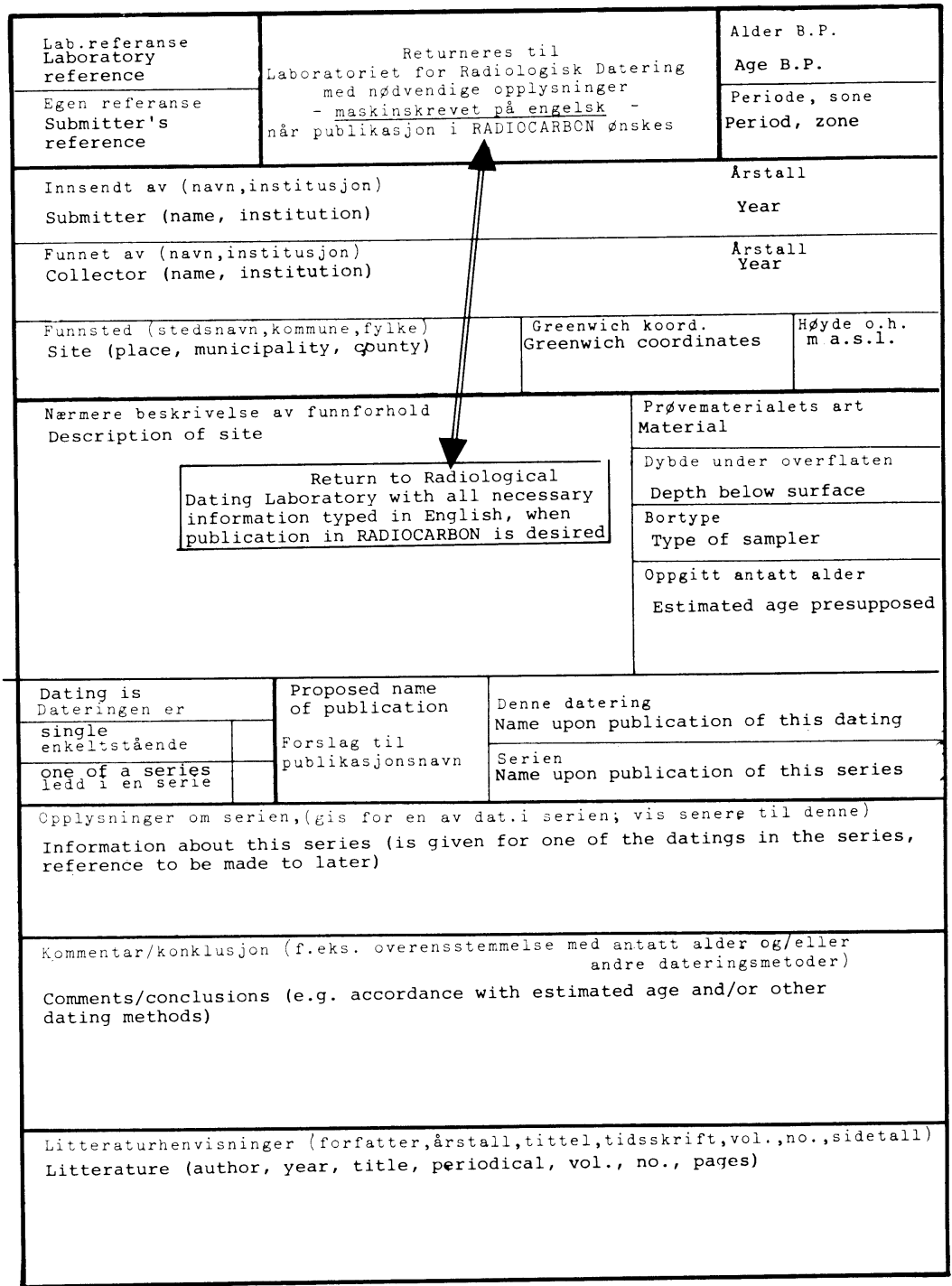

Fig 1. The form used at the Radiocarbon Dating Laboratory, Trondheim, Norway, upon publication of a ${ }^{14} \mathrm{C}$ date in Radiocarbon with our English translations

file containing such data that can be used with the main data base to solve this problem.

\section{VIDEO DISPLAY}

The 32 fields that make up a record are edited to fill a screen of 22 lines (Fig 3). The principal information can be easily seen. Some fields are joined to give the illusion of one field on the screen. The video display is quite compact as we have stretched dBASE II to its limits. 


\begin{tabular}{|c|c|c|c|}
\hline FLL & NAME & TYPE & WIUTH \\
\hline 001 & LABREF & c & 008 \\
\hline $00 z$ & OWNREF & c & 014 \\
\hline 003 & MUSNO & c & 013 \\
\hline 004 & $\mathrm{C} 13$ & C & 005 \\
\hline 005 & MATERIAL & c & 014 \\
\hline 006 & AGE & c & 015 \\
\hline 007 & MASCA & c & 015 \\
\hline 008 & PERIO[ & c & 027 \\
\hline 009 & ESTIMAGE & c & 011 \\
\hline 010 & WEIGHT & c & 005 \\
\hline 011 & KEYWORD1 & c & 065 \\
\hline 012 & KEYWOREZ & c & 055 \\
\hline 013 & SUEMI TYEAR & c & 024 \\
\hline 014 & INST I TUTE & $\mathrm{c}$ & 015 \\
\hline 015 & SITE & c & 015 \\
\hline 016 & MUNICIPAL & c & 016 \\
\hline 0.17 & COUNTY & c & 005 \\
\hline 018 & COUNTRY & c & 003 \\
\hline 019 & COORD & c & 010 \\
\hline 020 & ALTITUCEE & c & 004 \\
\hline 021 & DEPTH & c & 009 \\
\hline 022 & SINGLE & L & 001 \\
\hline 023 & SAMPNAME & C & 020 \\
\hline 024 & SERNAME & c & 030 \\
\hline 025 & DESCRIP 1 & c & 075 \\
\hline 026 & DESCRIPZ & c & 075 \\
\hline 027 & DESCRIP3 & c & 075 \\
\hline 028 & SERINFO1 & C & 075 \\
\hline 029 & SERINFOZ & $c$ & 075 \\
\hline 030 & SERINF 03 & $\mathrm{C}$ & 075 \\
\hline 031 & COMCONC1 & C & 075 \\
\hline & COMCONC2 & $\mathrm{c}$ & 075 \\
\hline & & & 10000 \\
\hline
\end{tabular}

Fig 2. The structure

\section{PRINTOUTS}

A small program has been implemented for a standard printout of the entire contents of each record, two per page (Fig 4). This program has been designed for FACIT 4510/4512 printers; with modifications, it may also be adapted to other printers. Editing resulted in five blocks of information: 1) sample numbers, ages, and material; 2) keywords; 3) submitter and geographic location of sample; 4) name of site and series; 5) description, comments, and references.

The last eight fields of the structure contain descriptive text which is printed out as if it were free text. Searching is possible in the fields of descriptive text as if they were one field. Gulliksen $(1983, \mathrm{p} 662)$ asked ${ }^{14} \mathrm{C}$ users of dates produced by the Trondheim ${ }^{14} \mathrm{C}$ laboratory to suggest parameters that ought to be available in his planned data base. Such a variety of terms were offered that he decided to work out a system capable of searching in free texts.

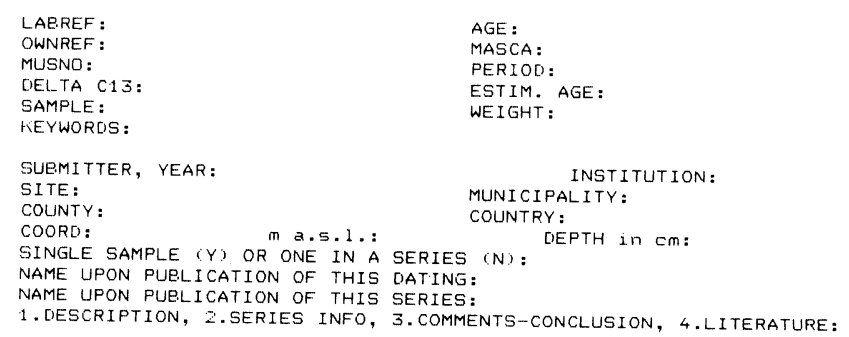

Fig 3. The video display 


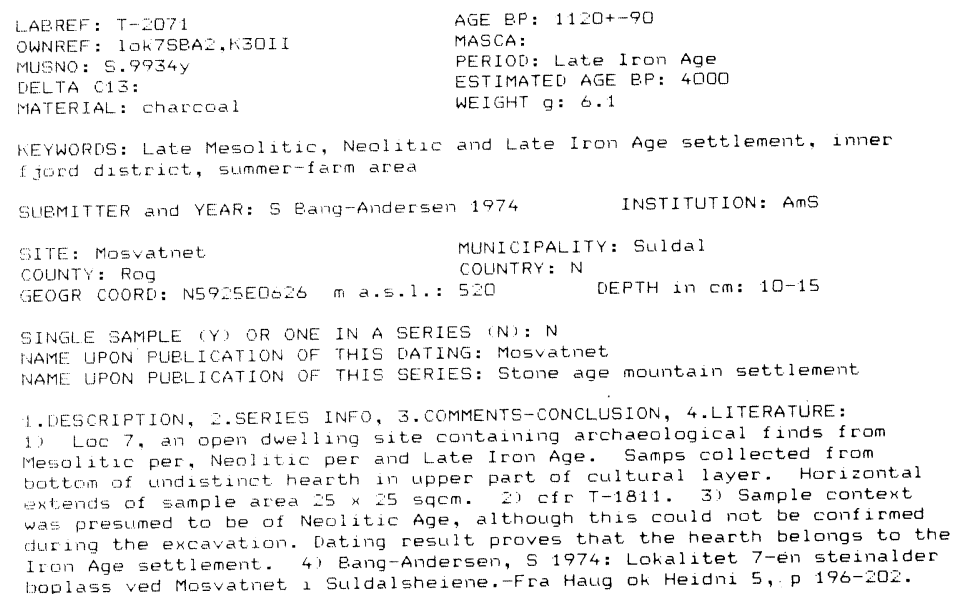

Fig 4. The printout

In our opinion, searching in free texts does not solve the problems described by Gulliksen. Terminology varies for different groups of users, eg, the same phenomenon may be described by several synonyms. To ensure complete retrieval of relevant information, Gulliksen (1983, p 662) defined macros, or groups of synonyms that can be used for retrieving documents in which at least one of the words appears. To avoid such free text searching, we have expanded the field, KEYWORDS, to provide more space for words precisely describing the dates. This expansion has been made at the expense of the descriptive text.

Printouts may be designed according to individual needs by using the command, REPORT. This command offers innumerable possibilities for printouts on various conditions in practically unlimited combinations of data.

\section{THE SEARCH}

The "C.14" data base is entered without a password, but a password may be established, if desired. Abbreviations listed in Kra (1984, p 157) are used in addition to others. Abbreviations for countries are those used internationally on motor vehicle license plates.

The search may contain conditions that are different combinations of various fields combined with logical operators such as AND, OR, NOT, >, $=,<$. All fields and parts of fields can be used in search operations. Commands like IOCATE, DISPI AY, CONTINUE, COUNT, LIST, REPORT, and GO TOP are often used. For further detailed use of commands, see dBASE II manual (1981).

dBASE II offers a wide range of search possibilities: searching in any number of fields, searching in any part of a field or in two or more parts of the same field, searching for an interval in one field or intervals in two fields, and searching in various combinations of the described search operations. 


\section{CONCLUDING REMARKS}

The "C14" data base program may be adapted to individual requirements and equipment with minor adjustments. In our opinion, dBASE II meets the requirements of a ${ }^{14} \mathrm{C}$ data base in a satisfactory way. The equipment and knowledge required to create and operate the "C14" data base are reasonable investments and adequately serve the needs of the radiocarbon community.

\section{ACKNOWLEDGMENTS}

We offer our sincere thanks to Else Iren Bjфrkhaug for typing the manuscript, Jan Mellemstrand for correcting the English, and our colleagues at the Arkeologisk museum i Stavanger for contributing with useful improvements to the "C14" data base.

\section{REFERENCES}

1981, dBASE II manual: Osborne Computer Corp, Hayward, California.

Bengtson, P, 1978, Guidelines for authors: Geol Fören Stockholm Förh, v 100, no. 1, p 7-17.

Gulliksen, S, 1983, Radiocarbon database: A pilot project, in Stuiver, $M$ and Kra, R S, eds, Internatl ${ }^{14} \mathrm{C}$ conf, $1 \mathrm{lth}$, Proc: Radiocarbon, v 25, no. 2, p 661-666.

Kra, R S, ed, 1984, Radiocarbon style guide: Radiocarbon, v 26, no. 1, p 152-158. 